*For correspondence: bjorn. gjelsvik@medisin.uio.no

Competing interests: The authors declare that no competing interests exist.

Received: 05 December 2018 Accepted: 17 December 2018 Published: 20 March 2019

(c) This article is Open Access: CC BY license (https://

creativecommons.org/licenses/ by/4.0/)

Author Keywords: type 2 diabetes, coronary heart disease, stroke, secondary prevention, general practice, primary care

Copyright (C) 2019, The Authors; DOI:10.3399/

bjgpopen18X101636

\section{Exploring the relationship between coronary heart disease and type 2 diabetes: a cross-sectional study of secondary prevention among diabetes patients}

Bjørn Gjelsvik, MD, PhD ${ }^{1 *}$, Anh Thi Tran, MD, PhD², Tore J Berg, MD, DrMedSci, ${ }^{3,4}$, Åsne Bakke, MD ${ }^{5,6}$, Ibrahimu Mdala, PhD7, Kjersti Nøkleby, MD ${ }^{8}$, John G Cooper, MD ${ }^{9,10}$, Tor Claudi, MD ${ }^{11}$, Karianne Fjeld Løvaas, MSc ${ }^{12}$, Geir Thue, MD, DrMedSci ${ }^{13,14}$, Sverre Sandberg, MD, DrMedSci ${ }^{15,16,17}$, Anne K Jenum, MD, DrMedSci ${ }^{18}$

${ }^{1}$ Assistant Professor, Department of General Practice, General Practice Research Unit (AFE), Institute of Health and Society, University of Oslo, Oslo, Norway; ${ }^{2}$ Researcher, Department of General Practice, General Practice Research Unit (AFE), Institute of Health and Society, University of Oslo, Oslo, Norway; ${ }^{3}$ Assistant Professor, Institute of Clinical Medicine, Faculty of Medicine, University of Oslo, Oslo, Norway; ${ }^{4}$ Senior Consultant, Department of Endocrinology, Morbid Obesity and Preventive Medicine, Oslo University Hospital, Oslo, Norway; ${ }^{5}$ Senior Consultant, Department of Medicine, Stavanger University Hospital, Stavanger, Norway; ${ }^{6}$ PhD Fellow, Department of Global Public Health and Primary Care, University of Bergen, Bergen, Norway; ${ }^{7}$ Statistician, Department of General Practice, General Practice Research Unit (AFE), Institute of Health and Society, University of Oslo, Oslo, Norway; ${ }^{8} \mathrm{PhD}$ Fellow, Department of General Practice, General Practice Research Unit (AFE), Institute of Health and Society, University of Oslo, Oslo, Norway; ${ }^{9}$ Researcher, Norwegian Quality Improvement of Laboratory Examinations, Haraldsplass Deaconess Hospital, Bergen, Norway; ${ }^{10}$ Senior Consultant, Department of Medicine, Stavanger University Hospital, Stavanger, Norway; ${ }^{11}$ Senior Consultant, Department of Medicine, Nordland Hospital, Bodø, Norway; ${ }^{12}$ Section Head, Norwegian Quality Improvement of Laboratory Examinations, Haraldsplass Deaconess Hospital, Bergen, Norway; ${ }^{13}$ Professor, Department of Global Public Health and Primary Care, University of Bergen, Bergen, Norway; ${ }^{14}$ Professor, Norwegian Quality Improvement of Laboratory Examinations, Haraldsplass Deaconess Hospital, Bergen, Norway; ${ }^{15}$ Professor, Laboratory of Clinical Biochemistry, Haukeland University Hospital, Bergen, Norway; ${ }^{16}$ Professor, Department of Global Public Health and Primary Care, University of Bergen, Bergen, Norway; ${ }^{17}$ Director, Norwegian Quality Improvement of Laboratory Examinations, Haraldsplass Deaconess Hospital, Bergen, Norway; ${ }^{18}$ Professor, Department of General Practice, General Practice Research Unit (AFE), Institute of Health and Society, University of Oslo, Oslo, Norway

\section{Abstract}


Background: Coronary heart disease (CHD) and stroke are the major causes of death among people with diabetes.

Aim: To describe the prevalence and onset of $\mathrm{CHD}$ and stroke among patients with type 2 diabetes mellitus (T2DM) in primary care in Norway, and explore the quality of secondary prevention.

Design \& setting: A cross-sectional study of data was undertaken from electronic medical records (EMRs) of 10255 patients with T2DM in general practice. The study took place in five counties of Norway (Oslo, Akershus, Rogaland, Hordaland, and Nordland). Quality of care was assessed based on national guideline recommendations.

Method: Summary statistics with adjustments and binary logistic regression models were used.

Results: In total, 2260 patients (22.1\%) had CHD and 759 (7.4\%) had stroke. South Asians had significantly more CHD than ethnic Norwegians $(29.5 \%, 95 \%$ confidence interval $[\mathrm{Cl}]=26.1$ to 33.0 versus $21.5 \%, \mathrm{Cl}=20.6$ to 22.3 ) and other ethnic groups, and experienced onset of CHD or stroke at a mean of 7 years before Norwegians. In $47.9 \%$ of the patients, CHD was diagnosed before T2DM. Treatment target for low-density lipoprotein (LDL) cholesterol was reached for $30.0 \%$ and for systolic blood pressure (SBP) for $65.1 \%$ of the patients with CHD. Further, $20.9 \%$ of patients with CHD were present smokers, and only $5.0 \%$ of patients reached all four treatment targets (no smoking, $\mathrm{HbA} 1 \mathrm{c} \leq 7.0 \%$, SBP $\leq 135 \mathrm{mmHg}$, LDL-cholesterol $\leq 1.8 \mathrm{mmol} / \mathrm{l})$.

Conclusion: The diagnosis of CHD preceded the diagnosis of T2DM in half of the patients. The prevalence of $\mathrm{CHD}$ was highest and onset earlier among ethnic South Asians. More intensive treatment of lipids, blood pressure, and smoking are needed in patients with T2DM and CHD.

\section{How this fits in}

CHD and stroke are prevalent among people with T2DM, and are generally thought to be a complication of diabetes. However, this survey found that diagnosis of CHD preceded the diagnosis of T2DM in half of the patients. An increased prevalence and earlier onset of CHD was also found among people of South Asian ethnicity. Only 30.0\% of CHD patients reached treatment target for LDL-cholesterol, and more intensive care is needed for people with multiple elevated risk factors.

\section{Introduction}

CHD and stroke are the major causes of death among people with diabetes. ${ }^{1}$ T2DM has been associated with a doubling of the risk for $\mathrm{CHD}$ and stroke, ${ }^{2}$ although a somewhat lower risk has recently been reported in Scandinavia. ${ }^{3,4}$ Cardiovascular disease (CVD) among patients with T2DM places pressure on the healthcare system, ${ }^{5,6}$ but multifactorial secondary prevention reduces morbidity and years of life lost. ${ }^{7-9}$

The influence of chronic hyperglycaemia on atherosclerosis is not fully understood, ${ }^{10}$ and studies describing the relation between the onset of CVD and of T2DM are few. There has, however, been an increasing awareness of diagnosing T2DM among patients with CHD. Recently, statins have been shown to exert a diabetogenic effect, ${ }^{11,12}$ which also may contribute to an increasing prevalence of T2DM among patients with CHD.

GPs follow up most patients with T2DM in Norway; therefore, the quality of care in general practice is essential for the clinical outcomes of these patients.

The aims in the present article were: firstly, to describe the prevalence of CHD and stroke among patients with T2DM, time of onset, and distribution according to age, sex, ethnic group, and region in a primary care setting in Norway; and secondly, to characterise the secondary preventive efforts among T2DM patients with CHD and stroke to identify potential treatment gaps, and identify patient and GP factors associated with successful achievement of treatment goals. 


\section{Method}

The study is part of the ROSA 4 study, which is a cross-sectional survey assessing the quality of care for patients with diabetes in general practice in Norway. In total, 106 practices with 367 GPs in five counties of Norway (Oslo, Akershus, Rogaland, Hordaland, and Nordland) were invited to the study. Detailed information about the method is available elsewhere. ${ }^{13}$

In short, a software program (Noklus) was used to identify all patients aged $\geq 18$ years with a diabetes diagnosis (using the ICPC-2 codes: T89 for diabetes type 1 and T90 for diabetes type 2) recorded from 2012-2014, and to capture pre-defined data from EMRs. Research nurses examined the EMRs to verify the electronically registered data and to collect other relevant data regarding diabetes care. A questionnaire was used to gather GPs' self-reported characteristics such as age, sex, and specialist status.

Variables used in the present study include the following: patient characteristics (such as age, sex, year of diabetes diagnosis, height, and weight); smoking status; pharmacological therapy; intermediate outcomes (including $\mathrm{HbA1c}$, blood pressure, total cholesterol, LDL-cholesterol, highdensity lipoprotein [HDL]-cholesterol and triglycerides); macrovascular complications (prevalence and year for diagnosis): CHD (angina, myocardial infarction, percutaneous coronary intervention/coronary artery bypass surgery), stroke (excluding transient ischaemic attacks); and atrial fibrillation (AF). For the majority of variables, the most recently recorded value from 1 October 2013-31 December 2014 was used; for smoking habits, the period was 1 January 2010-31 December 2014.

Further, Statistics Norway supplied information about country of birth and educational level. The patient's ethnic group was based on country of birth and was categorised as: (1) Norwegian (born in Norway); (2) South Asian (born in Pakistan, Sri Lanka, India, and Bangladesh); and (3) other. The patient's education was grouped into: (1) primary or no education; (2) high school and/ or vocational training; and (3) university education.

The quality of care was assessed according to key recommendations for treatment and treatment targets in the Norwegian guideline at the time of the survey; for example, the treatment target for $\mathrm{HbA} 1 \mathrm{c}$ was $\leq 7.0 \%$ (53 $\mathrm{mmol} / \mathrm{mol})$, intervention threshold for blood pressure was $>140 / 85 \mathrm{mmHg}$ with treatment targets $\leq 135 / 80 \mathrm{mmHg}$. In patients with CHD, the treatment target for LDL was $\leq 1.8$ $\mathrm{mmol} / \mathrm{l}$. Cardioprotective treatment with acetylsalicylic acid (ASA, commonly known as aspirin) 75 mg was recommended for T2DM with $\mathrm{CHD} .^{14}$

\section{Statistical analyses}

Crude prevalence of macrovascular complications and average adjusted prevalence with $95 \% \mathrm{Cl}$ stratified by sex, ethnic group, and county are reported.

Pharmacological treatment and intermediate outcomes ( $\mathrm{HbA} 1 \mathrm{c}, \mathrm{BP}$, and lipids) are reported for patients with CHD and stroke respectively. Descriptive statistics in the form of proportions, means (with standard deviations), or median values (with percentiles) were used to describe the patient characteristics by the stratification variables. Independent sample t-tests and analysis of variance (ANOVA) were used to compare mean differences of numerical variables between different patient groups. Associations between categorical factors were established from the $\chi^{2}$ tests.

The generalised estimating equation (GEE) binary logistic regression models with random effects at practice level were used to identify factors that were associated with achievement of treatment goals. Similar models were fitted to binary data on prevalence of CHD before and after the diagnosis of T2DM. All models were adjusted for patient-level characteristics (for example, age, sex, ethnic group, and education) while further adjustments using GP-level characteristics (for example, sex, and specialist status) were done in models assessing treatment goals. The analyses were performed with SPSS (version 24) and StataSE (version 15). Owing to multiple testing, the significance level was adjusted accordingly, based on the Bonferroni correction.

\section{Results}

Seventy-seven practices (72.7\% of those invited) with 282 GPs (76.3\% of those invited) agreed to participate, and provided data for 10255 patients with T2DM. The baseline characteristics and intermediate outcomes of these patients stratified according to sex and presence or absence of CHD and stroke are presented in Table 1. 


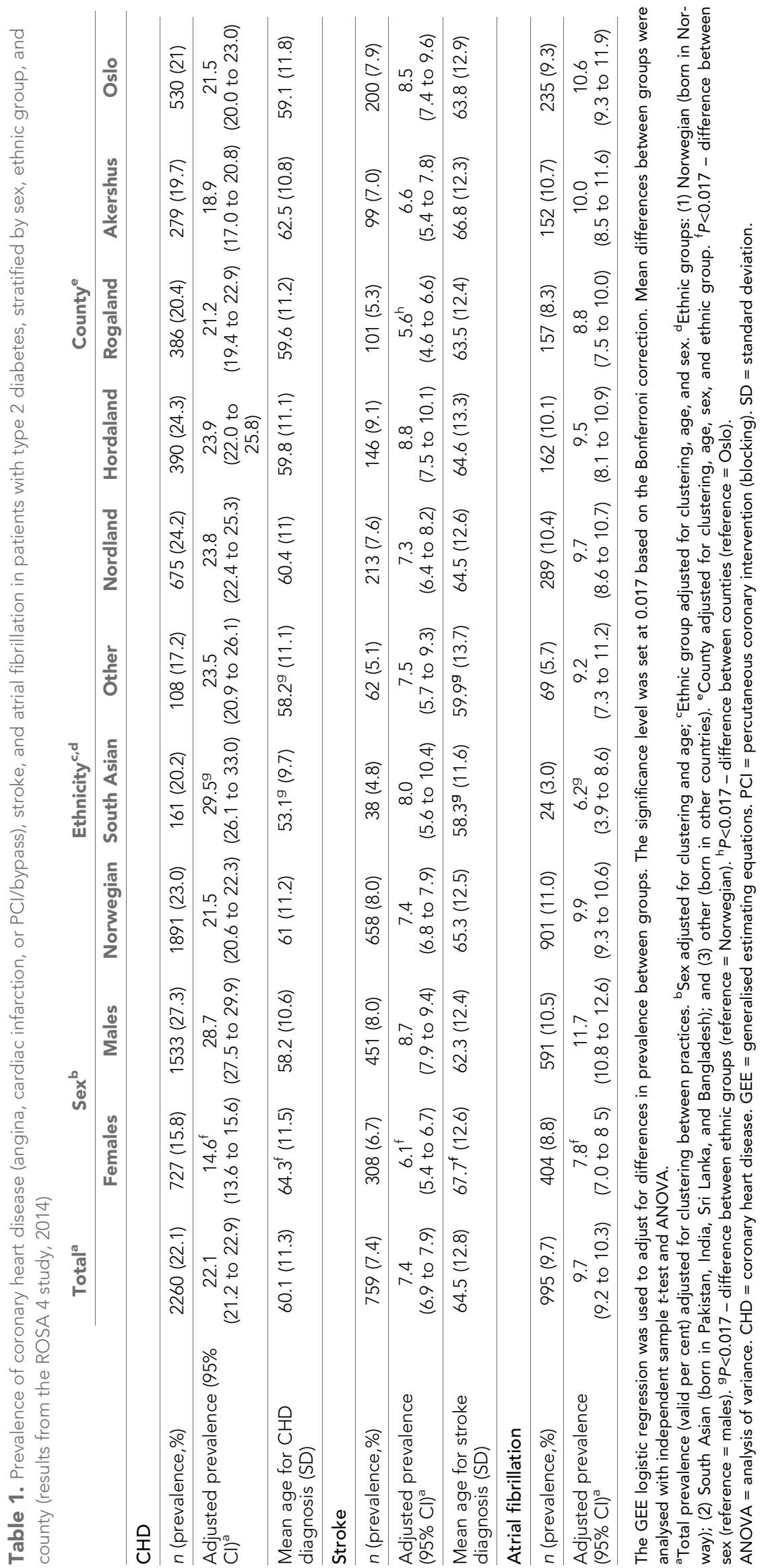




\section{Prevalence of CHD, stroke, and AF}

In total, 2260 patients $(22.1 \%$, missing data $=25)$ had $\mathrm{CHD}$ and $759(7.4 \%$, missing data $=9)$ had stroke reported in their EMRs (Table 1). Taken together, $30.9 \%$ of the patients had CHD, stroke, or $\mathrm{AF}$, or any combination of the three. The adjusted prevalence of $\mathrm{CHD}$ for males was twice the prevalence among females $(28.7 \%$ versus $14.6 \%)$, and there were significant differences between ethnic groups (Figure 1). These differences started at a young age and increased up to 64 years (further information available from the authors on request). The same sex difference, although to a lesser extent, was observed for stroke and AF. The mean age of onset for CHD and stroke was 7 years earlier in South Asians than in ethnic Norwegians. The prevalence of stroke was lower in Rogaland compared with the other counties.

\section{Relation between age of onset of CHD and T2DM}

The diagnosis of CHD preceded the diagnosis of T2DM by $\geq 1$ year for $50.2 \%$ of the Norwegian patients and $30.8 \%$ of the South Asian patients (Figure 2). The patients with CHD before T2DM were older, more often male, more often smokers, and had a lower educational level compared with the patients with CHD diagnosed after their T2DM diagnosis (additional information available from the author on request). A similar trend was observed for stroke, although the mean age of diagnosis for stroke was 1.8 years after the diagnosis of T2DM. For South Asians, CHD and stroke were diagnosed on average 4.3 years and 7.8 years after T2DM diagnosis respectively.

\section{Intermediary outcomes, treatment, and achievement of treatment targets for secondary prevention of CHD and stroke}

Only $5 \%$ of patients reached all four targets: $\mathrm{HbA} 1 \mathrm{c} \leq 7.0 \%, \mathrm{SBP} \leq 135 \mathrm{mmHg}$ or unmedicated $<140$ $\mathrm{mmHg}, \mathrm{LDL} \leq 1.8 \mathrm{mmol} / \mathrm{l}$, and no smoking (Table 2). The treatment target for $\mathrm{HbA} 1 \mathrm{c}$ was reached

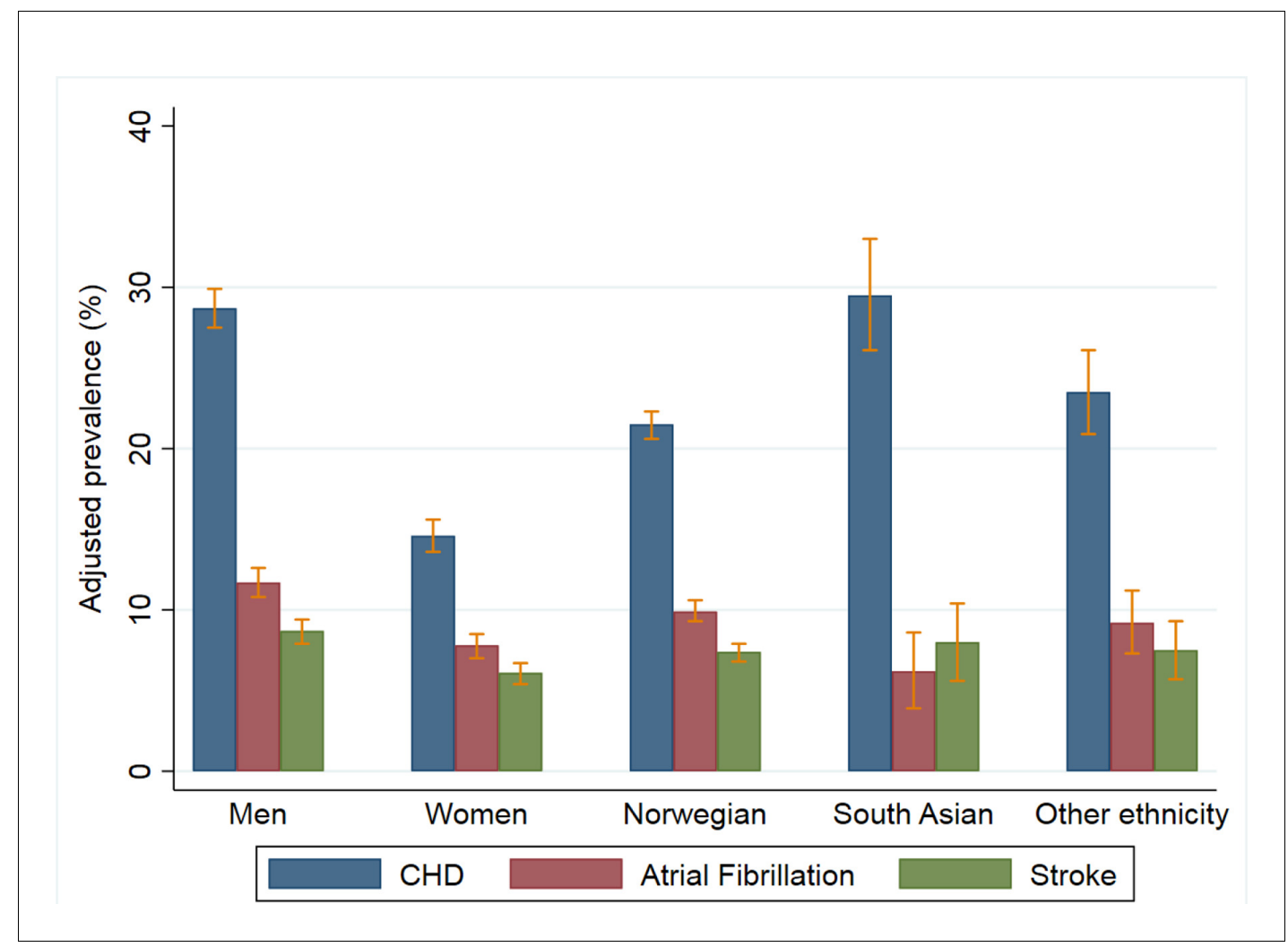

Figure 1. Adjusted prevalence of CHD, atrial fibrillation, and stroke by sex and ethnic group. Numbers for sex are adjusted for age and clustering within practices. Numbers for ethnic group are adjusted for age, sex, and clustering (see Table 1).

$\mathrm{CHD}=$ coronary heart disease. 


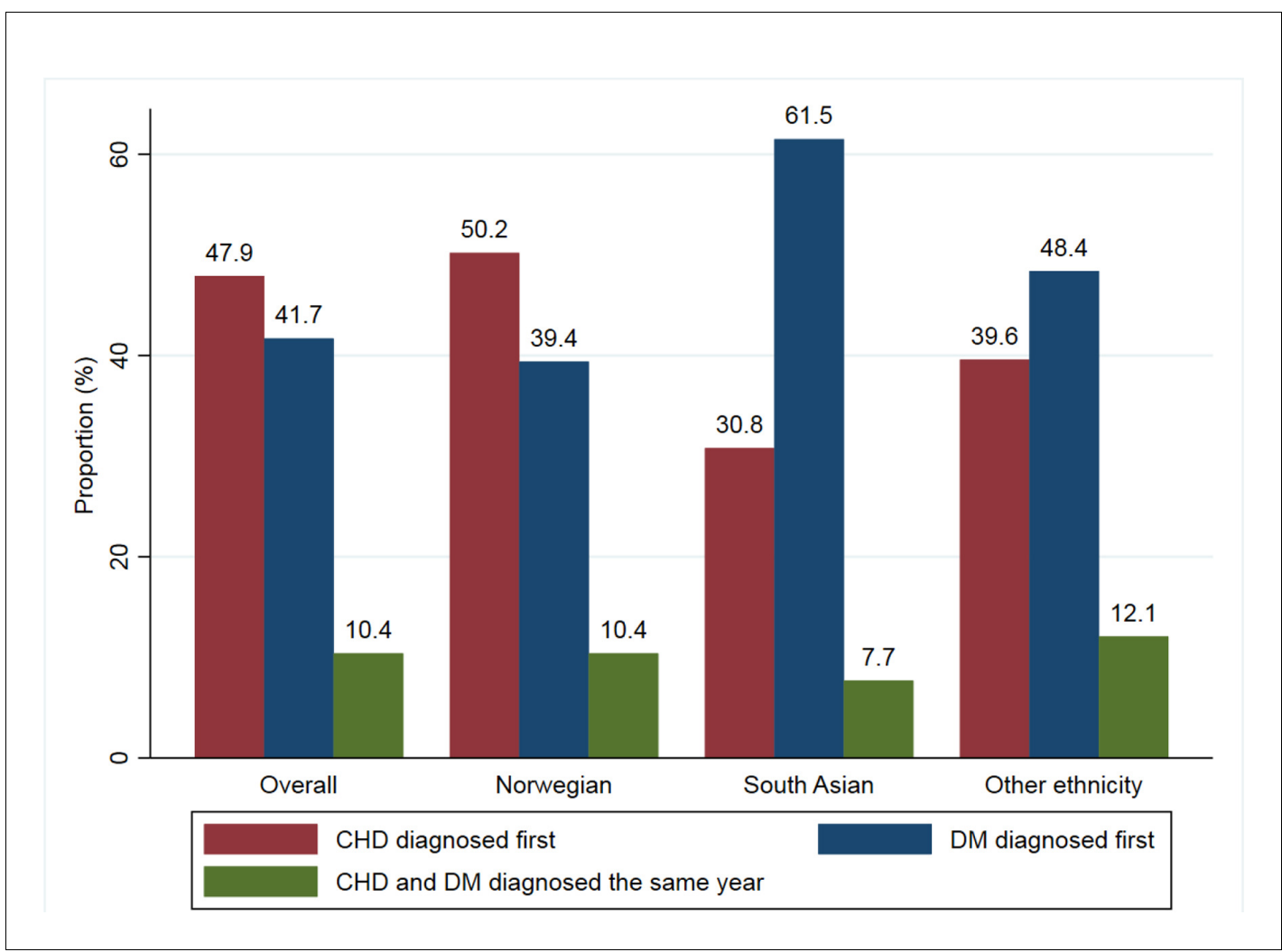

Figure 2. Proportions of patients where CHD was diagnosed $\geq 1$ year previously, the same year, and $\geq 1$ year after the diagnosis of type 2 diabetes (overall and in different ethnic groups)

$\mathrm{CHD}=$ coronary heart disease. $\mathrm{DM}=$ diabetes mellitus.

for $58.6 \%$ of the patients with CHD, while $65.1 \%$ achieved the SBP target. Among those who did not reach the SBP target, $14.3 \%$ were not prescribed antihypertensive medication by their GPs (Table 3). Treatment target for LDL-cholesterol $(\leq 1.8 \mathrm{mmol} / \mathrm{l})$ was reached for $30.0 \%$ of the CHD patients. A total of $77.3 \%$ of patients with $\mathrm{CHD}$ and $67.3 \%$ of patients with stroke used lipid-lowering agents. In total, $20.9 \%$ of the CHD patients were daily smokers. When patients aged $>80$ years were excluded, only minor changes in the percentages for treatment targets were observed (data not shown).

Patients with coexisting T2DM and CHD had more intensive antihypertensive treatment than those without CHD (Table 3). Beta-blockers, angiotensin-converting enzyme (ACE) inhibitors, angiotensin receptor blockers, and calcium channel blockers were more widely used in these patients, while the proportion using thiazides was approximately equal in the two groups. Of the patients with CHD, $74.6 \%$ used ASA.

In the models adjusted for confounders, females had an odds ratio (OR) of 0.64 (0.5 to 0.82) (reference $=$ males) for reaching treatment targets for LDL-cholesterol. However, females had an OR of 1.42 (1.16 to 1.74) for reaching SBP target (Table 4). Patients in the north of Norway (Nordland) also had lower odds for reaching the LDL-cholesterol target compared with other counties. People of South Asian and other ethnic groups had an OR of 0.42 (0.29 to 0.7$)$ for reaching the HbA1c target compared with ethnic Norwegians. People with a university degree had higher odds for reaching the $\mathrm{HbA} 1 \mathrm{c}$ and no smoking targets. 
Table 2. Proportion of patients with type 2 diabetes attaining treatment targets ${ }^{\text {a }}$ for $\mathrm{HbA} 1 \mathrm{c}$, SBP, lipids, and smoking, stratified by patient status regarding $\mathrm{CHD}$ and stroke

\begin{tabular}{|c|c|c|c|c|c|}
\hline Attained targets ${ }^{a}$ & & $\begin{array}{l}\text { With CHD, \% } \\
(n=2260)\end{array}$ & $\begin{array}{l}\text { Without CHD, \% } \\
\quad(n=7970)\end{array}$ & $\begin{array}{l}\text { With stroke, \% } \\
\quad(n=759)\end{array}$ & $\begin{array}{l}\text { Without stroke, \% } \\
\quad(n=9480)\end{array}$ \\
\hline $\begin{array}{l}\text { Targets and other cut- } \\
\text { off values }\end{array}$ & $\begin{array}{l}\text { Valid cases } \\
\text { (\%) }\end{array}$ & & & & \\
\hline \multicolumn{6}{|l|}{$\mathrm{HbA} 1 \mathrm{c}^{\mathrm{a}}$} \\
\hline$\leq 7.0 \%(\leq 53 \mathrm{mmol} / \mathrm{mol})$ & 89 & $58.6^{c}$ & 62.7 & 61.4 & 61.8 \\
\hline$>9.0 \%(>75 \mathrm{mmol} / \mathrm{mol})$ & & 6.7 & 6.1 & 6.7 & 6.1 \\
\hline \multicolumn{6}{|l|}{$\begin{array}{l}\text { Systolic blood pressure } \\
\text { (SBP) }^{\mathrm{a}}\end{array}$} \\
\hline $\begin{array}{l}\text { Percent attaining overall } \\
\text { SBP target }\end{array}$ & 74 & 65.1 & 65.7 & 66.7 & 65.6 \\
\hline $\mathrm{SBP}>140 \mathrm{mmHg}$ & 87 & 29.0 & 28.6 & 27.4 & 28.8 \\
\hline \multicolumn{6}{|l|}{ Lipids $^{a}$} \\
\hline $\begin{array}{l}\text { LDL-cholesterol } \leq 1.8 \\
(\mathrm{mmol} / \mathrm{l})\end{array}$ & 68 & 30 & - & - & - \\
\hline $\begin{array}{l}\text { LDL-cholesterol } \leq 2.5 \\
(\mathrm{mmol} / \mathrm{l})\end{array}$ & 68 & $67.9^{c}$ & 41.5 & $64.3^{c}$ & 46.2 \\
\hline \multicolumn{6}{|l|}{ Lifestyle } \\
\hline No daily smoking & 83 & $79.1^{b}$ & 76.9 & 76.4 & 77.5 \\
\hline
\end{tabular}

Proportions achieving specified number of targets

\begin{tabular}{lllll}
\hline Achieving no target & 8.0 & 10.8 & 8.4 & 8.9 \\
\hline Achieving one target & 92.0 & 90.5 & 91.6 & 91.1 \\
\hline Achieving two targets & 63.3 & 64.9 & 66.7 & 36.3 \\
\hline $\begin{array}{l}\text { Achieving three } \\
\text { targets }\end{array}$ & 27.9 & 29.8 & 33.7 & \\
\hline Achieving four targets & 5.0 & 6.0 & 7.9 & 7.0 \\
\hline
\end{tabular}

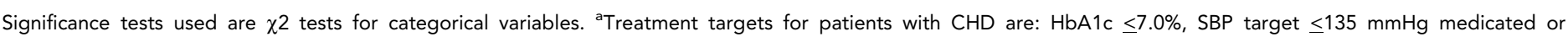
$\leq 140 \mathrm{mmHg}$ unmedicated, LDL-cholesterol $\leq 1.8 \mathrm{mmol} / \mathrm{l}$, no smoking. For patients without $\mathrm{CHD}$, the intervention threshold for LDL-cholesterol are LDL $>3.5 \mathrm{mmol} / \mathrm{l}$, with treatment target $\mathrm{LDL} \leq 2.5 \mathrm{mmol} / \mathrm{l} .{ }^{\mathrm{b}} P<0.05,{ }^{\mathrm{c}} P<0.001$.

$\mathrm{CHD}=$ coronary heart disease. $\mathrm{LDL}=$ low-density lipoprotein. $\mathrm{SBP}=$ systolic blood pressure.

\section{Discussion}

\section{Summary}

In this study, about one-third of the patients with T2DM had coexisting CHD, stroke, or AF, or a combination of these, and thus were candidates for secondary prevention. South Asians had the highest prevalence of CHD, and had the first event 7 years earlier than ethnic Norwegians. An important and novel finding is that in $50.2 \%$ of Norwegian patients with CHD the diagnosis of CHD preceded the diagnosis of T2DM by $\geq 1$ year. Treatment target for LDL-cholesterol was reached for $30.0 \%$ and for SBP for $65.1 \%$ of the patients with CHD. Further, $20.9 \%$ of patients with CHD were present smokers, and only $5.0 \%$ of patients reached all four treatment targets (no smoking, $\mathrm{HbA} 1 \mathrm{c}$ $\leq 7.0 \%, \mathrm{SBP} \leq 135 \mathrm{mmHg}$, LDL-cholesterol $\leq 1.8 \mathrm{mmol} / \mathrm{l})$.

For the patients with CHD, it is not obvious that CHD is a complication of T2DM. As the study is cross-sectional, possible explanations can only be speculated about. The trends for obesity and successive T2DM by ageing may be a factor, also among patients with CVD. CHD and T2DM have in common risk factors such as obesity, hypertension, and dyslipidaemia. However, patients where diagnosis of CHD preceded the diagnosis of T2DM were more often male, were older, and more often smokers or former smokers. Prevalent pre-diabetes or undiagnosed diabetes might also lead to CHD before the diagnosis of T2DM. Another possible explanation could be a hyperglycaemic 
Table 3. Prescriptions during the last 15 months for primary and secondary prevention in patients with type 2 diabetes, CHD, and stroke.

\begin{tabular}{|c|c|c|c|c|c|}
\hline \multirow[b]{2}{*}{ Treatment } & \multicolumn{3}{|c|}{ Primary prevention } & \multicolumn{2}{|c|}{ Secondary prevention } \\
\hline & $\begin{array}{c}\text { No CVD, \% } \\
n=7511\end{array}$ & $\begin{array}{l}\text { Females, \% } \\
n=3687\end{array}$ & $\begin{array}{l}\text { Males, \% } \\
n=3824\end{array}$ & $\begin{array}{l}\text { CHD, \% } \\
n=2260\end{array}$ & $\begin{array}{c}\text { Stroke, \% } \\
n=759\end{array}$ \\
\hline Attained SBP targets & 65.7 & 64.1 & $67.0^{\mathrm{a}}$ & 65.1 & 66.7 \\
\hline \multicolumn{6}{|l|}{ Blood pressure medication } \\
\hline Thiazides & 26.4 & 28.2 & 23.9 & 25.8 & 26.7 \\
\hline ACE inhibitors or all-receptor blockers & 47.7 & 48.7 & 46.8 & $61.5^{\mathrm{b}}$ & $58.0^{\mathrm{b}}$ \\
\hline Calcium channel blockers (dihydropyridines) & 23.1 & 22.3 & 23.8 & $29.1^{b}$ & $34.1^{\mathrm{b}}$ \\
\hline Beta-blockers & 16.9 & 19.0 & $14.9^{\mathrm{b}}$ & $65.6^{b}$ & $46.1^{\mathrm{b}}$ \\
\hline Other BP medication & 1.6 & 1.2 & $2.0^{\mathrm{a}}$ & $2.9^{b}$ & 2.2 \\
\hline Mean number of BP medications (SD) & $1.2(1.3)$ & 1.3 & 1.2 & $2.1(1.4)^{d}$ & $1.9(1.4)^{d}$ \\
\hline No BP medication & 42.8 & 39.5 & $46.0^{b}$ & $15.8^{\mathrm{b}}$ & $21.6^{\mathrm{b}}$ \\
\hline $\begin{array}{l}\text { Patients with SBP above target, and not prescribed } \\
\text { medication }\end{array}$ & 26.9 & - & - & 14.3 & 17.3 \\
\hline Attainment of LDL target & - & - & - & 30 & - \\
\hline \multicolumn{6}{|l|}{ Lipid-lowering medication } \\
\hline Statin & 45.5 & 45.6 & 45.4 & $76.7^{b}$ & $66.8^{\mathrm{b}}$ \\
\hline Ezetimibe & 1.6 & 1.9 & $1.3^{\mathrm{a}}$ & $4.7^{b}$ & 2.6 \\
\hline No lipid-lowering medication & 53.9 & 53.7 & 54.0 & $22.7^{b}$ & $32.7^{\mathrm{b}}$ \\
\hline Anti-platelet therapy & 22.8 & 21.6 & $24.1^{a}$ & $74.6^{b}$ & $66.3^{b}$ \\
\hline
\end{tabular}

Significance test performed with Poisson regression analysis comparing medication for males versus females, CHD versus non-CHD patients, and stroke versus non-stroke patients, respectively.

${ }^{\mathrm{a}} P<0.05$. ${ }^{\mathrm{b}} P<0.001$. Significance test performed with $\chi^{2}$ test comparing males versus females, $\mathrm{CHD}$ versus non-CHD, stroke versus non-stroke, respectively. ${ }^{\mathrm{C}} P<0.05 .{ }^{\mathrm{d}} P<0.001$.

$\mathrm{ACE}=$ angiotensin-converting enzyme. $\mathrm{BP}=$ blood pressure. $\mathrm{CHD}=$ coronary heart disease. $\mathrm{CVD}=$ cardiovascular disease. $\mathrm{LDL}=$ low-density lipoprotein. $\mathrm{SBP}=$ systolic blood pressure. $\mathrm{SD}=$ standard deviation.

effect of drugs used for secondary prevention of CHD (such as thiazides). Recently, statin treatment has been reported to exert such effects. ${ }^{11,12}$

Prescriptions for secondary prevention in patients with T2DM is largely in line with national recommendations with regard to medications in use. Of note, the most apparent gap in the quality of secondary prevention was that only $30.0 \%$ of patients with CHD reached the treatment target for LDL-cholesterol, despite more frequent use of statins than in $2005 .^{13}$ Still, $31.9 \%$ of the patients with CHD did not have the LDL-cholesterol measured within the preceding 15 months. Among those who did not achieve the LDL-cholesterol goal, 19.4\% did not use lipid-lowering drugs. Side effects of statins, or fear thereof, might have led to lower adherence to statin therapy or to the prescription of insufficient doses. ${ }^{15}$ It is also worth noting that, despite more prescription of antihypertensive drugs compared with the previous ROSA 3 survey in $2005,{ }^{13}$ a substantial number of patients with $\mathrm{CHD}$ and stroke were still undertreated for high blood pressure.

\section{Strengths and limitations}

The ROSA 4 study is the largest study of patients with T2DM in Norway. The selection of practices from three out of four health regions of Norway indicates that the sample is fairly representative for patients with T2DM treated by Norwegian GPs. The invited practices varied in size, and both urban and rural practices were included. The proportion of GPs with a specialist approval was somewhat higher than among all GPs in Norway (67.5\% versus $57.1 \%$ ). The mean number of patients on GPs' list was close to the mean for all GPs in Norway. Trained nurses manually validated the diagnosis of T2DM and CVD captured from the EMRs. The morbidity data were based on hospital reports, which ensured its accuracy. Socioeconomic variables were obtained from Statistics Norway, further assuring the validity of the study. 
Table 4. Associations between patient factors (including county of residence and education) and factors related to the GP, and the probability of achieving treatment targets for intermediate outcomes in patients with CHD and T2DM. ${ }^{a}$

SBP $\leq 135$ or $\leq 140^{b} \quad$ LDL-cholesterol $\leq 1.8 \mathrm{mmol} / \mathrm{I} \quad \mathrm{HbA} 1 \mathrm{c} \leq \mathbf{7 . 0} \% \quad$ No daily smoking

Covariates

OR $(95 \% \mathrm{Cl})$

OR $(95 \% \mathrm{Cl})$

OR $(95 \% \mathrm{CI})$

OR $(95 \% \mathrm{Cl})$

Patient factors

Age (per one year)

$1.03(1.02 \text { to } 1.04)^{d}$

1.00 (0.99 to 1.01$)$

1.00 (0.99 to 1.01$)$

$1.06(1.05 \text { to } 1.08)^{d}$

Sex (male $=$ reference $)$

$1.42(1.16 \text { to } 1.74)^{d}$

$0.64(0.50 \text { to } 0.82)^{d}$

1.11 (0.92 to 1.35$)$

0.97 (0.73 to 1.28$)$

Socioeconomic factors

County (Oslo $=$ reference)

Akershus

$0.98(0.59$ to 1.61$)$

0.79 (0.54 to 1.15$)$

0.98 (0.65 to 1.47$)$

1.14 (0.75 to 1.72$)$

Rogaland

1.05 (0.61 to 1.78 )

0.94 (0.67 to 1.33 )

1.07 (0.81 to 1.44 )

1.11 (0.74 to 1.67 )

Hordaland

1.02 (0.61 to 1.72 )

0.97 (0.71 to 1.34 )

0.94 (0.67 to 1.32 )

0.89 (0.59 to 1.34 )

Nordland

1.41 (0.85 to 2.35$)$

$0.60(0.42 \text { to } 0.85)^{d}$

0.94 (0.74 to 1.19$) \quad 1.26$ (0.83 to 1.93 )

Education (Primary/no education $=$ reference)

\begin{tabular}{|c|c|c|c|c|}
\hline Secondary education & $1.08(0.86$ to 1.35$)$ & $1.10(0.86$ to 1.40$)$ & $1.12(0.94$ to 1.34$)$ & 1.26 (0.96 to 1.65$)$ \\
\hline University & $0.95(0.67$ to 1.33$)$ & $1.14(0.83$ to 1.56$)$ & $1.34(1.02 \text { to } 1.76)^{c}$ & $1.76(1.18 \text { to } 2.61)^{\mathrm{c}}$ \\
\hline \multicolumn{5}{|c|}{ Ethnic group (Norwegian = reference) } \\
\hline South Asian & $0.94(0.63$ to 1.41$)$ & 1.21 (0.82 to 1.80$)$ & $0.45(0.29 \text { to } 0.7)^{d}$ & $1.91(1.19 \text { to } 3.06)^{c}$ \\
\hline Other & 1.05 (.72 to 1.54$)$ & 1.16 (0.79 to 1.58$)$ & $0.60(0.42 \text { to } 0.86)^{c}$ & 1.06 (0.67 to 1.68$)$ \\
\hline \multicolumn{5}{|l|}{ GP factors } \\
\hline \multicolumn{5}{|c|}{ Specialty (Yes = reference) } \\
\hline No & $1.24(0.91$ to 1.69$)$ & $0.95(0.72$ to 1.26$)$ & 0.92 (0.76 to 1.13$)$ & 1.15 (0.85 to 1.55$)$ \\
\hline \multicolumn{5}{|l|}{ Sex (Males = reference) } \\
\hline Females & $0.81(0.59$ to 1.11$)$ & 1.20 (0.91 to 1.57$)$ & 1.02 (0.85 to 1.22$)$ & $1.34(1.05 \text { to } 1.70)^{c}$ \\
\hline
\end{tabular}

${ }^{a}$ Multilevel binary logistic regression analyses with four dependent variables in 2260 T2DM patients with CHD, adjusted for clustering between practices. ${ }^{b}$ Systolic blood pressure targets: $<140 \mathrm{mmHg}$ for patients not using antihypertensives, and $<135 \mathrm{mmHg}$ when medication is prescribed. ${ }^{c} P<0.05 .{ }^{d} P<0.001$.

$\mathrm{Cl}=$ confidence intervals. $\mathrm{CHD}=$ coronary heart disease. $\mathrm{LDL}=$ low-density lipoprotein. $\mathrm{OR}=$ odds ratio. $\mathrm{SBP}=$ systolic blood pressure. $\mathrm{T} 2 \mathrm{DM}=$ type 2 diabetes mellitus.

However, the study has some limitations. It is not known why $27.4 \%$ of the practices declined to participate. The cross-sectional design limits the potential for exploring explanatory factors for differences in prevalence and intermediary outcomes.

\section{Comparison with existing literature}

The prevalence of CHD among patients with T2DM in the present study is comparable to findings from Sweden ${ }^{16}$ and from Cleveland, US. ${ }^{17}$ However, in a recent US multicentre register study with 575000 patients with diabetes, ${ }^{18}$ the prevalence of CHD was substantially higher (36.3\%), possibly reflecting a more selected population as several centres represented cardiology specialists.

The distribution of CHD and stroke by age, sex, and ethnic group in the present study is in line with other findings. ${ }^{19,20}$

The results regarding lipids are slightly better than found in secondary care in Europe, where $80 \%$ of CHD patients with T2DM had LDL $>1.8 \mathrm{mmol} / \mathrm{l} .{ }^{21} \mathrm{In}$ a recent Norwegian post-myocardial infarction study, mean LDL-cholesterol was $2.1 \mathrm{mmol} / \mathrm{l}$ and $57 \%$ did not reach the target for LDLcholesterol. $^{15}$

More patients from the present study had SBP $<140 \mathrm{mmHg}$ than in the Euroaspire III study (78\% versus $28 \%),{ }^{21}$ but the findings were comparable to recent results from the large US-based Diabetes Collaborative Registry. ${ }^{18}$

\section{Implications for research and practice}

The finding that CHD often preceded T2DM by several years calls for further research into the relationship between CHD and T2DM, and supports screening for diabetes among patients with CHD, such as measuring $\mathrm{HbA} 1 \mathrm{c}$ at the first event of $\mathrm{CHD}$ or stroke, and when CHD risk is assessed. ${ }^{22}$ 
Reasons for not taking statins among people with high risk for CVD events needs more qualitative investigation, and have implications for guidelines. Stricter treatment targets for intermediate outcomes need to be justified by a proper balance between benefits and harms, which represents a challenge in clinical practice. The target for LDL-cholesterol is to some extent arbitrary and GPs may feel that the target is too ambitious for some patients.

The proportion of patients reaching all targets will inevitably decline for every new target that is introduced, and likewise when targets for intermediate outcomes are lowered, if not counteracted by better support for self-management and compliance, including drugs with fewer side effects.

The increased prevalence of CHD and stroke, and younger age at diagnosis, among South Asians together with the fact that glycaemic control in South Asians is inferior compared with that of ethnic Norwegians, highlights the need for special attention towards this group.

Clinically, the groups with the highest blood pressure (SBP $>150 \mathrm{mmHg}$ ) have a clustering of risk factors and are in need of more effective preventive efforts. Lifestyle interventions - including strategies to support smoking cessation, intensified drug treatment, and support for better compliance might be needed for a substantial proportion of these high-risk patients. ${ }^{23}$

The diagnosis of CHD preceded the diagnosis of T2DM in half of the patients. Immigrants from South Asia deserve special attention as they have inferior glycaemic control and increased prevalence of $\mathrm{CHD}$ at a younger age than the majority population. There is a potential for improvements in secondary prevention, through more prescriptions of lipid-lowering drugs, smoking cessation, and better care for people with multiple elevated risk factors, including high blood pressure.

\section{Funding}

The affiliation organisation supports BG. ExtraStiftelsen supports ATT and ÅB. The data collection of the ROSA 4 study was supported financially with grants from the Norwegian Diabetes Association, a consortium of six pharmaceutical firms (AstraZeneca, Boehringer Ingelheim, Eli Lilly, MSD, Novo Nordisk, and Sanofi Aventis), Helse Nord, the Endocrinology Research Foundation, Stavanger, and the University of Oslo. The funders had no involvement in the study design, analysis and interpretation of the data, or in the writing of the report and revision of the paper. The contents of this publication are solely the responsibility of the authors.

\section{Ethical approval}

The Regional Ethical Committee approved the study (reference number: 2014/1374/REK Vest).

\section{Provenance}

Freely submitted; externally peer reviewed.

\section{Acknowledgements}

The authors wish to thank the GPs and the GP practices for participating in the study, and the research nurses who collected the data.

\section{References}

1. Matheus AS, Tannus LR, Cobas RA, et al. Impact of diabetes on cardiovascular disease: an update. Int J Hypertens 2013; 2013: 1-15. doi: 10.1155/2013/653789

2. Emerging Risk Factors Collaboration, Sarwar N, Gao P, Seshasai SR, et al. Diabetes mellitus, fasting blood glucose concentration, and risk of vascular disease: a collaborative meta-analysis of 102 prospective studies. Lancet 2010; 375(9733): 2215-2222. doi: 10.1016/S0140-6736(10)60484-9

3. Jortveit J, Kaldal A, Tonstad S. Prevalence of diabetes before and after first diagnosis of coronary artery disease. Tidsskr Nor Laegeforen 2018; 138(5). doi: 10.4045/tidsskr.17.0539

4. Tancredi M, Rosengren A, Svensson AM, et al. Excess mortality among persons with type 2 diabetes. $N$ Engl $J$ Med 2015; 373(18): 1720-1732. doi: 10.1056/NEJMoa1504347

5. Haw JS, Narayan KM, Ali MK. Quality improvement in diabetes - successful in achieving better care with hopes for prevention. Ann N Y Acad Sci 2015; 1353: 138-151. doi: 10.1111/nyas.12950

6. Vaidya V, Gangan N, Sheehan J. Impact of cardiovascular complications among patients with Type 2 diabetes mellitus: a systematic review. Expert Rev Pharmacoecon Outcomes Res 2015; 15(3): 487-497. doi: 10.1586/14737167.2015.1024661

7. Gæde $P$, Oellgaard J, Carstensen B, et al. Years of life gained by multifactorial intervention in patients with type 2 diabetes mellitus and microalbuminuria: 21 years follow-up on the Steno-2 randomised trial. Diabetologia 2016; 59(11): 2298-2307. doi: 10.1007/s00125-016-4065-6

8. Gaede $\mathrm{P}$, Lund-Andersen $\mathrm{H}$, Parving $\mathrm{HH}$, et al. Effect of a multifactorial intervention on mortality in type 2 diabetes. N Engl J Med 2008; 358(6): 580-591. doi: 10.1056/NEJMoa0706245 
9. Griffin SJ, Borch-Johnsen K, Davies MJ, et al. Effect of early intensive multifactorial therapy on 5-year cardiovascular outcomes in individuals with type 2 diabetes detected by screening (ADDITION-Europe): a cluster-randomised trial. Lancet 2011; 378(9786): 156-167. doi: 10.1016/S0140-6736(11)60698-3

10. Leon BM, Maddox TM. Diabetes and cardiovascular disease: Epidemiology, biological mechanisms, treatment recommendations and future research. World J Diabetes 2015; 6(13): 1246-1258. doi: 10.4239/ wjd.v6.i13.1246

11. Danaei G, García Rodríguez LA, Fernandez Cantero O, et al. Statins and risk of diabetes: an analysis of electronic medical records to evaluate possible bias due to differential survival. Diabetes Care 2013; 36(5): 1236-1240. doi: 10.2337/dc12-1756

12. Crandall JP, Mather K, Rajpathak SN, et al. Statin use and risk of developing diabetes: results from the Diabetes Prevention Program. BMJ Open Diabetes Res Care 2017; 5(1): e000438. doi: 10.1136/bmjdrc2017-000438

13. Bakke $\AA$, Cooper JG, Thue G, et al. Type 2 diabetes in general practice in Norway 2005-2014: moderate improvements in risk factor control but still major gaps in complication screening. BMJ Open Diabetes Res Care 2017; 5(1): e000459. doi: 10.1136/bmjdrc-2017-000459

14. Helsedirektoratet (Norwegian Health Directorate). [National guideline for diabetes: prevention, diagnosis and treatment] Nasjonal faglig retningslinje for diabetes (in Norwegian). 2017; https://helsedirektoratet.no/ retningslinjer/diabetes (accessed 11 Mar 2019).

15. Munkhaugen J, Sverre E, Otterstad JE, et al. Medical and psychosocial factors and unfavourable low-density lipoprotein cholesterol control in coronary patients. Eur J Prev Cardiol 2017; 24(9): 981-989. doi: 10.1177/ 2047487317693134

16. Rawshani A, Rawshani A, Franzén $S$, et al. Mortality and cardiovascular disease in type 1 and type 2 diabetes. N Engl J Med 2017; 376(15): 1407-1418. doi: 10.1056/NEJMoa1608664

17. Pantalone KM, Hobbs TM, Wells BJ, et al. Clinical characteristics, complications, comorbidities and treatment patterns among patients with type 2 diabetes mellitus in a large integrated health system. BMJ Open Diabetes Res Care 2015; 3(1): e000093. doi: 10.1136/bmjdrc-2015-000093

18. Arnold SV, Goyal A, Inzucchi SE, et al. Quality of care of the initial patient cohort of the Diabetes Collaborative Registry ${ }^{\circledR}$. J Am Heart Assoc 2017; 6(8):e005999. doi: 10.1161/JAHA.117.005999

19. Gregg EW, Li Y, Wang J, et al. Changes in diabetes-related complications in the United States, 1990-2010. N Engl J Med 2014; 370(16): 1514-1523. doi: 10.1056/NEJMoa1310799

20. Chaturvedi N, Fuller JH. Ethnic differences in mortality from cardiovascular disease in the UK: do they persist in people with diabetes? J Epidemiol Community Health 1996; 50(2): 137-139. doi: 10.1136/jech.50.2.137

21. Gyberg V, Kotseva K, Dallongeville J, et al. Does pharmacologic treatment in patients with established coronary artery disease and diabetes fulfil guideline recommended targets? A report from the EUROASPIRE III cross-sectional study. Eur J Prev Cardiol 2015; 22(6): 753-761. doi: 10.1177/2047487314529353

22. Helsedirektoratet (Norwegian Health Directorate). [National guidelines for prevention of cardiovascular diseases] Nasjonal faglig retningslinje for forebygging av hjerte- og karsykdom (in Norwegian). 2017; https:// helsedirektoratet.no/retningslinjer/forebygging-av-hjerte-og-karsykdom (accessed $11 \mathrm{Mar}$ 2019).

23. Edelman SV, Polonsky WH. Type 2 diabetes in the real world: the elusive nature of glycemic control. Diabetes Care 2017; 40(11): 1425-1432. doi: 10.2337/dc16-1974 